\title{
A função da arte teatral na educação infantil: o teatro particular de cada criança
}

\author{
The role of the theater art in early childhood education: the private \\ theater of every child
} http://dx.doi.org/10.5007/2178-4582.2016v50n1p50

\section{Humberto Moacir de Oliveira}

Faculdade Pitágoras de Ipatinga, Ipatinga/MG, Brasil.

Camila Rodrigues Vaz Chaves

Universidade Federal de Minas Gerais, Belo Horizonte/MG, Brasil.

Jacques Fux

Universidade Estadual de Campinas, Campinas/SP, Brasil.

\begin{abstract}
Partindo da ideia aristotélica de que é na tendência a representar que repousa a capacidade de aprender do homem, o presente artigo visa discutir, através de uma revisão bibliográfica, quais seriam os mecanismos psíquicos que possibilitariam essa operação e quais papeis o teatro poderia exercer na educação infantil. Para tanto, foi imprescindível articular a discussão de Freud a respeito da fantasia à teoria sobre o ensino do teatro de Ingrid Koudela para, então, trazer uma contribuição à discussão sobre a forma como esse rico veículo de representação que é o teatro pode contribuir com o desenvolvimento da criança.

Palavras-chave: Teatro; Educação; Psicanálise.
\end{abstract}

Starting from Aristotle's idea that human's ability to learn relies on the tendency to represent, the current article aims to discuss, through a literature review, the psycho mechanisms that enable such operation, and the roles played by theater on children's education. Therefore, it was imperative to articulate Freud's discussion regarding fantasy to the theory of Ingrid Koudela on theater education in order to make a contribution to the discussion on how theater - which is a rich vehicle of representation - may contribute to the child development.

Keywords: Theater; Education; Psychoanalysis.

\section{Introdução}

Um dos axiomas inaugurais da Poética proferidos por Aristóteles (1984) é de que o homem, desde a infância, traz consigo uma tendência à representação, assim como uma considerável capacidade de retirar prazer dessa atividade. A observação das brincadeiras infantis e sua proximidade com a arte faz com que a afirmação aristotélica não perca seu valor mesmo passado mais de dois mil anos. Segundo o autor, toda arte, principalmente todo texto dramático, é uma imitação, apenas se diferindo quanto ao meio, ao objeto ou ao modo de se imitar. É a imitação que permite, ainda segundo Aristóteles, que o espectador se identifique com a arte e sofra as conseqüências dessa identificação: o riso diante da comédia, que imita homens piores do que ordinariamente são; e a piedade e o terror na tragédia, que imita homens superiores aos que ordinariamente encontramos. 
Essas afirmações nos permitem supor que toda criança traz consigo o germe da atividade artística e uma inclinação tanto a fazer arte quanto a comprazer com a apresentação de uma obra. Porém, a afirmação aristotélica nos leva a dar um passo a mais quando afirma que é essa capacidade humana de imitar que coloca o homem em posição mais favorável do que a de outros animais: "O imitar é congênito no homem (e nisso difere dos outros viventes, pois, de todos, é ele o mais imitador, e, por imitação, aprende as primeiras noções), e os homens se comprazem no imitado." (ARISTÓTELES, 1984, p.243).

Estamos aqui no limiar de uma teoria da educação: é imitando, representando, que os homens aprendem as primeiras noções, e reside nesse processo uma das vantagens do ser humano diante dos outros animais. A representação, dessa maneira, vem reivindicar o seu lugar na educação. É bom lembrar que representação aqui não necessariamente refere-se ao trabalho do ator, e sim a uma característica que Aristóteles encontra em toda e qualquer arte, o que sugere a possibilidade da atividade artística se oferecer como ferramenta a colaborar no processo de o homem de aprender, por imitação, suas primeiras noções.

Essa ideia de que a representação, seja na arte ou no jogo lúdico, apresenta-se como uma das atividades que colaboram com a educação da criança é reconhecida, como veremos, por teorias psicodinâmicas e teatrais. No entanto, mais do que perguntar se a ludicidade da representação desempenha ou não um papel no desenvolvimento infantil e no processo de assimilação da cultura, o que aqui será questionado é como o mundo fantasioso da brincadeira e da arte interfere na vida dos seres humanos a tal ponto de colocá-los em uma posição privilegiada diante dos demais viventes. Tal questionamento pretende contribuir e incentivar o debate sobre políticas e técnicas educacionais que procuram incluir, pensar e discutir, o teatro na educação formal.

Responder a essa pergunta não é apenas elaborar técnicas de como inserir o teatro na educação infantil, nem propor regras e limites para o uso do lúdico nas escolas. As discussões sobre essas tarefas nós encontramos em diversos debates sobre o assunto. Porém, tão importante quanto pensar a técnica e a política da entrada do teatro na educação, é conhecer e reconhecer a função subjetiva da atividade teatral e sua relação com o psiquismo humano. A elucidação desses pontos, por mais modesta que seja, empresta à presente discussão uma sustentação ética e teórica para o tema.

Perseguindo esse objetivo de trazer alguma elucidação teórica sobre a relação da arte com o desenvolvimento do psiquismo humano, nossa pesquisa lançará mão dos estudos psicanalíticos, principalmente dos textos freudianos, 
a respeito da arte e do brincar, para articulá-los a algumas teorias sobre o ensino do teatro, na sua mais ampla concepção, que extrapola em muito a estrita formação de atores. Nessa aproximação entre o campo psicanalítico e o campo teatral é que apostamos encontrar maiores esclarecimentos sobre a maneira como o teatro particular ${ }^{1}$ de cada criança, suas fantasias, e o uso que ela faz dele, torna-se elementar para toda e qualquer teoria da educação que se preocupe não apenas com a transmissão de informações, mas principalmente com a assimilação do mundo e da cultura pelos infantes, que se tornam, nessa perspectiva, mais do que simples aprendizes, sujeitos do seu processo educativo.

\section{O teatro particular da criança: fantasia, arte e desenvolvimento infantil}

A mesma ideia de Aristóteles de que a representação e a imitação auxiliam a criança na aquisição das suas primeiras noções do mundo pode ser encontrada hoje em diversos teóricos que abordam a inserção do teatro na educação. É o que encontramos, por exemplo, na pesquisa de Teixeira e Camargo (2010), quando os autores resgatam a perspectiva de Courtney que enxerga a imitação como um dos primeiros meios do aprendizado humano.

Uma posição semelhante parece ser defendida pelo diretor teatral britânico Declan Donnellan: "Desenvolvemos nossa identidade interpretando papeis que vemos fazer nossos pais, e expandimos nossa identidade ainda mais copiando personagens que vemos representados por irmãos maiores, irmãs, amigos, rivais, professores, inimigos ou heróis." (DONNELLAN, 2007, p.14). A imitação sugerida por ambos os autores é a imitação em sua perspectiva aristotélica: mais versão, recriação, do que cópia. Desta forma, a imitação, marcantemente presente na arte, é essencial para a criança reelaborar o mundo, apropriar-se dele e adaptá-lo.

Mas como se dá esse processo? Um dos caminhos que podemos recorrer para responder essa pergunta surge no início do século XX, quando Sigmund Freud, encantado com suas novas descobertas sobre o funcionamento mental, esforça-se para articular sua teoria com as mais diversificadas atividades humanas, desde os sonhos até a religião, passando, por diversas vezes, pela atividade artística. Perante esta última, o pai da psicanálise se detém: "Já que o talento artístico e a capacidade estão intimamente ligados à sublimação,

$1 \quad$ O termo "teatro particular" como equivalente das fantasias presentes nos devaneios aparece na teoria psicanalítica pela primeira vez através da boca de Ana O., reconhecida por Freud como a primeira paciente a se beneficiar de uma psicanálise. Segundo o autor, a paciente "Embelezava sua vida (...) entregando-se a devaneios sistemáticos que descrevia como seu "teatro particular"” (FREUD, [1895]/1996, v..2, p.58). O termo será reutilizado na psicanálise como modo de denunciar a relação entre o fantasiar e a dramaturgia teatral, relação explorada mais detalhadamente por Freud em 1908 . 
temos de admitir que a natureza da função artística também não pode ser explicada através da psicanálise". (FREUD,[1910],1996, p.140). Embora, de fato, a atividade artística permaneça sendo um dos mistérios mais íntimos de cada artista (e por vezes um mistério para o próprio artista), a psicanálise freudiana pôde, sim, ampliar a teoria sobre a relação que a humanidade mantém com a arte.

Ainda que tenha se debruçado sobre obras de artistas consagrados como Leonardo da Vinci, Dostoievski, Sófocles, Shakespeare, entre outros, foi na representação infantil que Freud recolheu considerável parte de sua teoria sobre o papel que a arte desempenha no desenvolvimento ontogenético e filogenético do ser humano. Em "Escritores criativos e devaneios", Freud ([1908]/1996) aponta o brincar infantil como protótipo do fazer artístico e, por ser mais precoce e primordial que ele, sua investigação nos possibilitaria ter maiores esperanças de obter algumas explicações do trabalho do artista.

Para nossa finalidade, no entanto, a diferença entre brincar e arte interessa menos do que como essas atividades que Aristóteles chama "imitações" podem ajudar a criança em seu processo civilizatório de inserção na cultura. Aqui, percebemos que, como Aristóteles, também Freud aposta no mundo representativo como uma das mais tenras ferramentas utilizadas pelo homem para aprender suas primeiras noções. Pois, para Freud, o brincar, como equivalente infantil da arte, é um dos motores desse processo: "O brincar da criança é determinado por desejos: de fato, por um único desejo - que auxilia o seu desenvolvimento -, o desejo de ser grande e adulto" (FREUD, [1908]/1996, p.137).

Como notamos acima, Freud intensifica a importância do brincar para o desenvolvimento da criança e aposta que é um desejo que a guia rumo a esse desenvolvimento. Nesse momento de sua teoria, Freud aposta que é o desejo de ser adulto que faz com que a criança se desloque da realidade e imerja no mundo da fantasia, sem perder a realidade de vista, o que seria enlouquecer. Aliás, é exatamente nesse ponto que a teoria psicanalítica sobre o brincar contribui com a teoria do fazer artístico, pois será também guiado por seus desejos que o artista investirá sua energia psíquica em um mundo de representações.

Para entender esse processo de como o desejo guia o sujeito para o campo da fantasia sem enlouquecê-lo - ponto fundamental para a elucidação da forma pela qual a arte vem colaborar com a aprendizagem do ser humano - é preciso que penetremos no conceito psicanalítico de fantasia. Ao escrever o texto "Formulações sobre os dois princípios de funcionamento mental", Freud ([1911]/1996) irá dizer que a fantasia participa das atividades humanas como 
uma maneira de fuga da realidade, porém uma fuga parcial, já que o sujeito conserva as outras funções de seu organismo psíquico investidas na realidade. Ou seja, uma parte de nossas atividades de pensamento é liberada do teste de realidade e permanece subordinada somente ao que é reconhecido pelo psiquismo como uma fonte de prazer. Nas palavras de Freud, isso é o fantasiar, “(...) que começa já nas brincadeiras infantis, e, posteriormente, conservada como devaneio, abandona a dependência de objetos reais." (FREUD, [1911]/1996, p.241).

Curioso, no entanto, é o fato de, ao contrário de outras fugas da realidade observadas por Freud, como no sintoma neurótico e na psicose, a fuga da realidade presente nas fantasias da brincadeira e da atividade artística ser entendida por ele como um processo que auxilia o ser humano em seu desenvolvimento e não em seu adoecimento. A explicação para essa questão está no fato de as pessoas adoecerem, de uma forma ou de outra, por frustrações, ou seja, quando a realidade as impede de satisfazer seus desejos. $\mathrm{Se}$, como vimos anteriormente, por um lado, as frustrações impostas pela realidade auxiliam o sujeito em seu desenvolvimento fazendo-o ligar-se à realidade mais do que à fantasia que lhes dá prazer, por outro, essas mesmas frustrações são motivos de adoecimento caso o sujeito não encontre maneiras de elaborá-las. O mundo lúdico, as representações artísticas, os contos de fadas, o faz de conta, são maneiras de o sujeito elaborar essas frustrações através da representação. Em "Inibições, sintomas e ansiedade", texto muito posterior aos analisados aqui, Freud dará uma explicação mais direta a essa ideia:

\footnotetext{
O ego, que experimentou o trauma passivamente, agora o repete ativamente, em versão enfraquecida, na esperança de ser ele próprio capaz de dirigir seu curso. É certo que as crianças se comportam dessa maneira em relação a toda impressão aflitiva que recebem, reproduzindo-a em suas brincadeiras. Ao passarem assim da passividade para a atividade tentam dominar suas experiências psiquicamente. (FREUD, [1926]/1996, p.162).
}

Tentar dominar as experiências psiquicamente é uma forma de simbolizar o que no mundo carece de significação e o que no psiquismo é vivido como trauma. É isso que levará o psicanalista francês - autor, ator e diretor de teatro, François Regnault - a dizer, a partir dos ensinamentos de Lacan, que o teatro organiza o vazio em seu espaço e que assim “...realiza alguma anamorfose em sua representação - do crânio, na tragédia, por que não, e por que não do falo, na comédia" (REGNAULT, 2001, 160). O teatro organiza e transforma o vazio na medida em que o vazio carece de significação, de imitação, de representação. Na falta de representação do vazio, representa-se com o teatro, 
com a fantasia que busca recobrir o real carente de significação. Uma das fórmulas ${ }^{2}$ que Lacan ([1960]/1997) irá propor para arte é justamente que uma obra de arte é um modo de organização em torno do vazio, o que a coloca, pelo menos em parte, distante da religião, que evita o vazio, e da ciência, que não crê nesse vazio.

Para esclarecer essas três formas de tratamento do vazio destacadas por Lacan - a religião, a ciência e a arte -, podemos acrescentar à nossa discussão o trabalho do filósofo Alain Badiou (1996), que distingue três grandes orientações de pensamento que tentam, cada uma à sua maneira, resolver o problema do que aparece no mundo simbólico como um excesso impossível de ser assimilado completamente pelo sujeito, e que a psicanálise também vem a designar o que conhecemos por trauma.

Assim, seguindo Badiou, a orientação de pensamento transcendente seria aquela marcada pela pressuposição de um ente superior que ordenaria com sua lei universal tudo o que se encontra em seu domínio. O excesso, o inassimilável pelo significante, ficaria dessa forma sob o jugo desse ser superior - que as religiões designam por Deus - o que nos ajuda a compreender a fala de Lacan de que a religião busca, através de seus rituais, evitar o encontro com esse furo significante.

A ciência, por sua vez, estaria mais próxima do que Badiou denomina de pensamento de orientação construtivista, que procura colocar todas as experiências no campo do saber, ou seja, em um campo onde elas possam ser nomeadas e designadas pelos parâmetros de um referencial paradigmático. Em outras palavras, o que não faz parte desse referencial paradigmático, não existe, e só passará a existir a partir do momento em que puder ser incluído, nomeado, mensurado e quantificado por esses referenciais. Retomando o raciocínio de Lacan, podemos dizer que a ciência, então, descrê no que não é assimilável pelos seus arranjos significantes.

Teríamos, por fim, a orientação de pensamento genérico, a qual podemos pensar ser mais adequada para os esforços artísticos, estejamos ou não na esfera da educação infantil. Enquanto as orientações anteriores negam o excesso, o furo, o vazio de significação, evitando-os através de rituais ou descrendo de sua existência e de seus efeitos, na orientação de pensamento genérico, o excesso é admitido, sendo considerado parte essencial do processo de linguagem e mesmo necessário para sua existência.

2 Segundo Máximo Recalcati (2005), podemos demarcar três dimensões estéticas em Lacan: a estética anamórfica, que promove, através da arte, um encontro do espectador com a impossibilidade de representação, com a desconstrução da moldura do representável, ou ainda, com o que Lacan chama de mancha; a estética da letra, que promove uma redução significante, apostando mais no caráter assemântico do significante do que no sentido que os significantes podem provocar através de um encadeamento; e a estética do vazio, que encara a obra de arte como um contorno do vazio irrepresentável, que é exatamente a fórmula que Regnault (2001) destaca em sua leitura sobre o teatro. 
Todas as três orientações de pensamento representam o que Freud designou, como vimos acima, por uma tentativa de dominar psiquicamente experiências traumáticas, entendendo por traumático tudo o que comporta um excesso impossível de ser assimilado pelo sujeito. A arte se destacaria, portanto, por, ao invés de evitar ou descrer no vazio, se organizar exatamente em torno desse furo. Para elucidar essa proposta, Lacan cita a obra do oleiro que faz o vaso a partir do furo, do vazio. $\mathrm{O}$ artista seria aquele que faz algo a partir desse furo que insiste em todo processo de linguagem.

Mais uma vez podemos nos valer das palavras quase poéticas de Donnellan, que como usuário da língua e homem de teatro percebe a impossibilidade de assimilarmos através da expressão simbólica e significante tudo o que nosso corpo experimenta: "Sempre há um vazio entre o que sentimos e nossa habilidade para expressar o que sentimos. Quanto mais desejamos reproduzir esse vazio e quanto mais queremos dizer "a verdade", mais amplo se abre o perverso eco." (DONNELLAN, 2007, p.16).

No entanto, a criança não tem o teatro ou outra forma de expressão artística sistematizada para organizar algo em torno desse vazio que se reproduz em nossas tentativas de expressar o que sentimos e, se tem, à arte dela damos o nome, equivocadamente ou não, de brincadeira. Ofertar à criança novas possibilidades de representação daquilo que em seu mundo carece de representação não livra a criança da neurose nem de sintomas futuros, não é a salvação da humanidade e muito menos da educação infantil, mas contribui com o exercício infinito do homem em lidar com esse vazio sem evitá-lo, como o faz a religião, nem descrê-lo, como sugere a ciência.

Além da fantasia, que auxilia o ser humano a organizar-se em torno do vazio através da brincadeira e da arte, vimos que Freud destaca também o desejo de ser adulto como uma das contribuições do lúdico no desenvolvimento da criança. A base dessa ideia reside na maneira como a criança lida com seus primeiros objetos amorosos, a saber, os primeiros adultos cuidadores. A realidade se impõe para a mais tenra criança, que logo percebe a função que o adulto exerce não só em sua sobrevivência como nos próprios meios dela alcançar o prazer. É por esse motivo que uma parte do amor que a criança inicialmente dedica à si própria é transferida para os adultos mais próximos, e apenas com algum custo, será transferida mais tarde a outras crianças. A criança, assim, passa a amar o adulto - e o amor para psicanálise não consiste apenas em ter o objeto e gozar de sua companhia, mas também em ser o objeto ideal ou assemelhar-se a ele.

Em "O ego e o id" ([1923]/1996), Freud, ao propor a divisão do aparelho psíquico em "Eu", "Isso" e "Supereu", afirma que se o $E u$, como parte do 
psiquismo, se assemelhar ao objeto amado, o Isso, outra parte do psiquismo, poderá amar o $E$ u como se este fosse o próprio objeto. Em outras palavras, se uma criança se assemelha ao adulto amado, ela pode amar essa parte de si que se identificou com esse adulto. Nesse sentido, é bastante notável os meninos que buscam usar os sapatos do pai ou as meninas que buscam maquiar-se como a mãe, identificando seu $E u$ ao objeto amado. De um modo mais sutil, esse mesmo mecanismo de identificação ao objeto amado é encontrado em brincadeiras como as de papai e mamãe, nas quais as crianças exercem a função de um ou de outro membro do par parental, e que em geral detestam fazer o papel dos filhos; ou nas brincadeiras de casinha, que novamente reconstituem o ambiente familiar; ou, ainda, nas brincadeiras de médico, que além de satisfazer o desejo de se identificar com o adulto permite que a criança explore o corpo humano; isso sem falar nos contos de fadas e, por que não, os teatros, que muitas vezes representam príncipes e princesas que superam dificuldades grandiosas, possíveis de serem superadas apenas por adultos fortes e ricos e, não raramente, belos.

Tudo isso confirma a hipótese de que muitas atividades infantis sejam guiadas pelo desejo de ser adulto. Mas ainda deixa uma pergunta sobre como esse desejo pode interferir a favor do desenvolvimento humano. Essa pergunta talvez encontre uma elucidação quando lembramos que a criança participa ativamente desse processo de representação da vida e do mundo adulto, incorporando-o ao mesmo tempo em que o inventa. É através desse processo de assimilação e de invenção com o que vem do campo do grande Outro (campo que na psicanálise lacaniana inclui tanto o pequeno outro, ou seja, seu semelhante, quanto a cultura e o mundo em que o sujeito está mergulhado), é que a criança constitui o seu Eu, desde seu caráter até suas características mais gerais.

No entanto, isso não quer dizer, evidentemente, que a arte deva exercer o papel moral de transmitir à criança um modelo de se guiar pelo mundo. O que pode ser formulado é que o mundo da representação, encontrado na brincadeira e na arte, deve ampliar o modo da criança incorporar a cultura e o mundo, ao mesmo tempo em que se constrói como sujeito.

\section{O teatro social da criança: os jogos teatrais e a educação infantil}

Já tendo penetrado na teoria psicanalítica para tentar compreender as operações subjetivas que fazem com que a arte possa servir como instrumento capaz de enriquecer o desenvolvimento humano, é hora de nos voltarmos para o teatro e perguntarmos como essa atividade pode ser inserida em uma experiência educacional - isso, claro, sem querer esgotar as diversas leituras e formas de se pensar a introdução do teatro na educação. 
Retomando a comparação freudiana entre a arte e a brincadeira, percebemos que não apenas a construção artística como também sua apreciação funcionam como o equivalente dos jogos infantis. Em "Personagens psicopáticos no palco", Freud ([1942]/1996) afirma que para a plateia de um teatro, participar do jogo dramático é também uma maneira de ampliar as formas de obtenção de prazer através da fantasia. Portanto, a brincadeira serve à criança como a arte serve ao artista e ao público, e, por sua vez, não é menos séria do que ela: "A antítese de brincar não é o que é serio, mas o que é real." (FREUD, [1908]/1996, p.135). O teatro, por ser ele uma atividade imitativa por excelência, permite, portanto, que autores, atores e público possam exercitar suas fantasias, assim como desenvolver a criatividade e a imaginação.

Sendo assim, a criança tanto quando brinca como quando entra em contato com a arte, como em um espetáculo teatral, alimenta, por meio da imitação, sua criatividade. Segundo Maria Clara Machado (1972), a emoção artística leva a criança a um mundo de fantasia e de sonho que corresponde ao que busca sua alma em desenvolvimento. Por meio de espetáculos assistidos a criança se identifica, se comunica e desenvolve sua capacidade de captar o mundo da mesma forma que quando uma criança escuta uma história, um conto de fadas, ela desvenda o mundo real através do lúdico, do fictício.

O que Maria Clara Machado chama de capacidade de captar o mundo, vai ao encontro da discussão psicanalítica mencionada anteriormente sobre a relação da criança com o Outro, encarnado não apenas nos pais e nos adultos mais próximos, como em toda a cultura e muitos objetos que a cercam e que não fazem parte do seu $\mathrm{Eu}$. $\mathrm{O}$ teatro aparece nesse contexto como um dos operadores que continua estimulando a criança a usar sua criatividade e subjetividade para descobrir e captar o mundo objetivo que a cerca e que exige dela sempre inúmeros desafios de diversificadas ordens (prática, cognitiva, emocional, etc.).

Mas é importante destacar ainda que o teatro se apresenta para a criança além dessa dimensão de faz de conta citada, como acabamos de ver, por Maria Clara Machado. Ele se apresenta também enquanto jogo, o que, além do caráter imaginativo do faz de conta, preza também pela inserção e intensificação de regras sociais importantes para o convívio em grupo.

Para Ingrid Koudela (1998), pesquisadora da didática do teatro, o contato com o jogo teatral pela criança pode ser entendido como ferramenta para a transformação do jogo simbólico (subjetivo) no jogo de regras (socializado). Ainda segundo a autora, o jogo instiga e faz emergir uma energia do coletivo quase esquecida, pouco utilizada e compreendida, muitas vezes depreciada. Por estar em jogo com o grupo, a criança trabalha o contato com 
o outro, o desenvolvimento em conjunto, a troca de saberes, a espontaneidade (ainda que em presença de regras), além da desinibição e observação.

Essas duas funções do teatro, destacadas por Machado e por Koudela, poderia nos levar a fazer uma distinção entre a função do "faz de conta" do teatro (espetáculo que aguça a criatividade e a imaginação da criança) e sua função enquanto jogo teatral (atividade que insere e trabalha regras sociais). Porém, visto essa divisão ser bastante relativa, já que podemos encontrar o faz de conta nos jogos, assim como podemos encontrar a socialização nos espetáculos, preferimos pensar o teatro na educação de modo amplo, com suas múltiplas propostas, tanto de faz de conta, quanto de jogo.

É preciso ressaltar ainda que quando estamos falando do trabalho criativo ou do trabalho social dos jogos, ainda não estamos nos referindo à atuação das crianças no palco. Essa ressalva não é desprovida de valor, principalmente quando notamos que durante o aprendizado escolar a preocupação maçante em criar espetáculos com crianças tende mais a levá-las ao exibicionismo e à competição do que à estimulação da subjetividade e da vida em grupo, principalmente quando os profissionais envolvidos deixam de lado o desenvolvimento que os jogos teatrais podem trazer, em troca de um produto final a ser exibido aos pais, familiares e demais professores. Nesse sentido, concordamos com a afirmação de Fanny Abramovich, arte-educadora que diz:

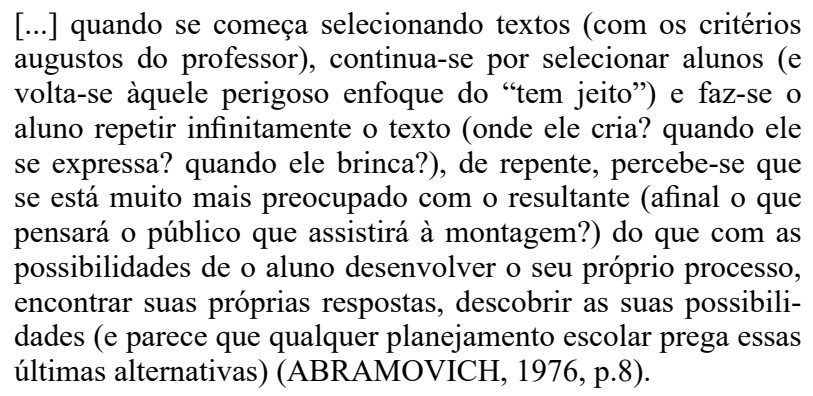

Sugerindo uma solução para essa questão, Koudela afirma: "Entre o jogo de faz-de-conta da criança e o teatro, como espetáculo a ser apreciado por uma platéia, é possível criar inúmeras gradações, promovendo atividades que relacionam o fazer e a leitura do espetáculo teatral" (KOUDELA, 2011, s/p.). Assim, como intensifica a autora no trecho citado, existem várias possibilidades gradativas entre o faz de conta e o espetáculo teatral, e é nessas gradações que podemos encontrar um rico material a ser explorado através do teatro na educação.

Desta forma, por mais variada que seja a inclinação de cada criança à arte, o importante em seu desenvolvimento é que tenha contato com o lúdico que 
essa atividade comporta, sem que se confunda lúdico com falta de planejamento ou com diversão gratuita. Os jogos teatrais, o brincar, a representação das variadas artes e formas de reinvenção através do imitar, serão assim ferramentas valiosas para expandir o potencial criativo, cognitivo e social da criança, e importarão mais do que o produto a que se chegará em cada trabalho. Como pudemos ver através da ótica psicanalítica, o lúdico é essencial para a formação do adulto, para o desenvolvimento da sensibilidade, escuta, criatividade e percepção do ser humano (ampliando as possibilidades de lidar com o mal estar e com o vazio anteriormente citado) e não deve ser massacrado por ideais estéticos e morais do profissional que coordena as atividades.

Assim, para a criança, a arte funciona como o espetáculo teatral para o adulto. Segundo Freud ([1908]/1996), quando o espectador assiste a um espetáculo, ele se depara com seus próprios devaneios, no entanto, modificados no palco de tal forma que o faz despir parcialmente de sua autoacusação ou vergonha, sentindo assim grande prazer em vê-los sendo realizados por um ator, porque desta forma o espectador não sofre as possíveis dores e tribulações que realizar suas fantasias poderiam lhe causar. Obviamente, essas formulações teóricas, como Freud reconhece, estão já no cerne da teoria de Aristóteles (1984) sobre a tragédia e sobre seu mecanismo mais peculiar: a catarse. Talvez possamos acrescentar que um mecanismo semelhante será usado também para livrar o espectador da carga imposta pela realidade através da ironia e do humor de uma comédia. Nas palavras de Regnault (2001), nos encontramos entre o crânio de Shakespeare e o falo de Aristófanes.

Percebendo a importância da arte na vida do adulto, é fácil supor novamente sua importância talvez ainda maior na vida da criança que está em fase aguda de assimilação do mundo e da cultura, de aprendizado e de formação. A arte e a fantasia, com seu faz de conta e seus jogos de socialização expandem o repertório de imitação, de simbolização e de expressão de sentimentos da criança e, por isso, se fazem tão necessárias na constituição saudável do sujeito adulto.

\section{Considerações finais}

É através do lúdico que conseguimos perceber, adaptar e mudar a realidade que nos rodeia, criando sobre nós mesmos uma visão crítica sobre a nossa existência e nossos desejos. É aguçando nossa sensibilidade que desenvolvemos responsabilidade pelo coletivo e enriquecimento individual. Dessa forma, incentivar a brincadeira e o contato da criança com a arte, com o faz de conta e com o jogo, não só no teatro, mas intensificados nele, é contribuir com a formação de adultos comunicativos, sociáveis, sensíveis, críticos, 
criativos e perceptivos, o que facilita sua vivência no mundo social e sua capacidade de captá-lo e agir sensivelmente sobre ele.

O que podemos destacar é que o teatro, seja na sua função de apresentar o faz de conta, seja na sua dimensão de jogo social, não resolverá o problema da educação, que continuará sendo sempre, como alertou Freud (1937/1996), uma das profissões impossíveis quanto às quais de antemão se pode estar seguro de chegar a resultados insatisfatórios. No entanto, reconhecendo o importante papel que a arte e o teatro cumpriram desde os tempos mais remotos da civilização, é impossível desconsiderá-lo como uma importante ferramenta para o desenvolvimento do ser humano.

Nesse sentido, o presente artigo representa uma contribuição na elucidação desse processo, ainda que seja fato reconhecido que muitas outras questões se fazem presentes nessa relação entre o teatro e a educação, desde os aspectos mais internos e subjetivos até seus aspectos mais técnicos, políticos e sociais. O vazio da falta de respostas não deve desestimular o educador; afinal, ele deve se lembrar de que evitar esse vazio seria se portar como o religioso, ao passo que tentar preenchê-lo a qualquer custo seria ser cientista demais. Por vezes, o educador deve se portar tal qual o artista ou a criança e, livre da imposição da verdade, organizar-se em torno desse buraco como o faz o oleiro na fabricação de seu vaso.

\section{Referências}

ABRAMOVICH, Fanny. Teatro na educação (o que é, afinal?). In: BRASIL (Ministério da Educação e Cultura, Serviço Nacional de Teatro). Teatro na Educação: subsídios para seu estudo. Rio de Janeiro, 1976, p.8-11.

ARISTÓTELES. Poética. Trad. Eudoro de Sousa. São Paulo: Victor Civita, 1984. p. 105 (Trabalho originalmente publicado no século IV a.C.)

BADIOU, Alain. O ser e o evento. Rio de Janeiro: JZE, 1996. 402 p.

DONNELLAN, Declan. El actor y la diana. Trad. em língua espanhola por Ignacio García May. 2a ed., Madrid: Editorial Fundamentos, 2007.208 p.

FREUD, Sigmund. Estudos sobre histeria. In: FREUD, S. Edição standard das obras psicológicas completas de Sigmund Freud. Rio de Janeiro: Imago, 1996, v.2, p.13-318 (Trabalho originalmente publicado em 1895).

Escritores Criativos e devaneios. In: FREUD, S. Edição standard das obras psicológicas completas de Sigmund Freud. Rio de Janeiro: Imago, 1996, v. 9, p.133-146 (Trabalho originalmente publicado em 1908). 
Leonardo Da Vinci e uma lembrança de sua infância. In: FREUD, S. Edição standard das obras psicológicas completas de Sigmund Freud. Rio de Janeiro: Imago, 1996, v.11, p.67-141 (Trabalho originalmente publicado em 1910).

.Formulações sobre os dois princípios de funcionamento mental. In: FREUD, S. Edição standard das obras completas de Sigmund Freud. Rio de Janeiro: Imago, 1996, v.. 12, p. 233 246 (Trabalho originalmente publicado em 1911).

. O Ego e o Id. In: FREUD, S. Edição standard das obras psicológicas completas de Sigmund Freud. Rio de Janeiro: Imago, 1996, v.. 19, p. 15-82 (Trabalho originalmente publicado em 1923).

.Inibições, sintomas e ansiedade. In: FREUD, S. Edição standard das obras psicológicas completas de Sigmund Freud. Rio de Janeiro: Imago, 1996, v. 20, pp. 81-174 (Trabalho originalmente publicado em 1926).

Análise terminável e interminável. In: FREUD, S. Edição standard das obras psicológicas completas de Sigmund Freud. Rio de Janeiro: Imago, 1996, v.. 23, p. 225-273 (Trabalho originalmente publicado em 1937).

FREUD, S. Personagens psicopáticos no palco. In: FREUD, S. Edição standard das obras psicológicas completas de Sigmund Freud. Rio de Janeiro: Imago, 1996, v. 7, p. 289-298 (Trabalho originalmente publicado em 1942).

KOUDELA, Ingrid Dormien. Jogos Teatrais. São Paulo: Perspectiva, 1998. 155 p.

.. A ida ao teatro. Sistema Cultura é currículo, São Paulo, s.d. Disponível em: <http:// culturaecurriculo.fde.sp.gov.br/administracao/Anexos/Documentos/420090630140316A\%20 ida\%20ao\%20teatro.pdf> . Acesso em: 30 out. 2011.

LACAN, Jacques. O Seminário, livro 7: a ética da psicanálise. Rio de Janeiro: Jorge Zahar Editor, 1997. 396 p. (Trabalho originalmente publicado em 1960)

MACHADO, Maria Clara. Teatro na Educação. Cadernos de Teatro, 52, 1, 6-10, 1972. Disponível: <http://otablado.com.br/wp-content/uploads/notebooks-theater/9f0fd81b6e197a555c8632f25dfde0c1.pdf.> Acesso em: 10 mai. 2016.

RECALCATI, Massimo. As três estéticas de Lacan. Opção Lacaniana, n42. São Paulo: Eolia, 2005, p. 94-108.

REGNAULT, François. Em torno do vazio: a arte à luz da psicanálise. Rio de Janeiro: Contra Capa, 2001. 167 p.

TEIXEIRA, Ana Paula; CAMARGO, Robson Corrêa de. Spolin e Stanislavski: Intersecções no ensino e na prática do teatro. Revista de História e Estudos Culturais, [S.1.], v. 7. Ano VII, $\mathrm{n}^{\circ} 1$, jan./abr.2010.

Submissão em: 15/12/2014

Revisão em: 20/09/2015

Aceite em: 27/09/2015 
Humberto Moacir de Oliveira é professor da Faculdade Pitágoras de Ipatinga (FAP), Campus Horto. Mestre em Psicologia pela Universidade Federal de Minas Gerais (UFMG). Coordenador do CEPP (Centro de Estudo e Pesquisa em Psicanálise do Vale do Aço). Endereço para correspondência: Rua Cedro, 317, ap. 701, Bairro Horto, Ipatinga/ MG. CEP 35160-296. E-mail: beto7296@yahoo.com.br

Camila Rodrigues Vaz Chaves é bacharela em Teatro pela Universidade Federal de Minas Gerais (UFMG) e mestranda em Artes (com ênfase em artes da cena) também na UFMG. Integrante do Estúdio Fisções, grupo de pesquisa da UFMG, foi atriz nos espetáculos: "A Família de Arthur" (Grupo Atempus), "A viagem de Thespis" (Antônio Hildebrando), "Cortejo Abre-Alas" (Grupos Lume e Trampolim), "Galileu na Piscina" (Grupo Olho Nu), "Rojas Rosas" (Grupo Medéias), "Clara manhã de quinta à noite" (Estúdio Fisções) e "Os que são pagos para delirar \#sqn" (Marina Viana e Marina Arthuzzi). E-mail: caca_rvc@hotmail.com

Jacques Fux é Pós-doutor em Teoria Literária pelo Instituto de Estudos da Linguagem da UNICAMP. Doutor em Literatura Comparada na UFMG (POS-LIT - 2010)

em cotutela com a Universidade de Lille 3 (2010). Autor dos livros: Literatura e Matemática: Jorge Luis Borges, Georges Perec e o OULIPO (Tradição Planalto, 2011); Antiterapias (Scriptum, 2012) e Brochadas: Confissões sexuais de um jovem escritor (Rocco, 2015). Email:jacfux@gmail.com 